\title{
Height and risk of death among men and women: aetiological implications of associations with cardiorespiratory disease and cancer mortality
}

George Davey Smith, Carole Hart, Mark Upton, David Hole, Charles Gillis, Graham Watt, Victor Hawthorne hood. The inverse association between height and stomach cancer mortality probably reflects Helicobacter pylori infection in childhood resulting in-or being associated with-shorter height. The positive associations between height and several cancers unrelated to smoking could reflect the influence of calorie intake during childhood on the risk of these cancers.

(F Epidemiol Community Health 2000;54:97-103) land.

Design-Prospective observational study. Setting-Renfrew and Paisley, in the West of Scotland.

Subjects-7052 men and 8354 women aged 45-64 were recruited into a study in Renfrew and Paisley, in the West of Scotland, between 1972 and 1976. Detailed assessments of cardiovascular disease risk factors, morbidity and socioeconomic circumstances were made at baseline.

Main outcome measures-Deaths during 20 years of follow up classified into specific causes.

Results-Over the follow up period 3347 men and 2638 women died. Height is inversely associated with all cause, coronary heart disease, stroke, and respiratory disease mortality among men and women. Adjustment for socioeconomic position and cardiovascular risk factors had little influence on these associations. Height is strongly associated with forced expiratory volume in one second $\left(F E V_{1}\right)$ and adjustment for $F_{1} V_{1}$ considerably attenuated the association between height and cardiorespiratory mortality. Smoking related cancer mortality is not associated with height. The risk of deaths from cancer unrelated to smoking tended to increase with height, particularly for haematopoietic, colorectal and prostate cancers. Stomach cancer mortality was inversely associated with height. Adjustment for socioeconomic position had little influence on these associations.

Conclusion-Height serves partly as an indicator of socioeconomic circumstances and nutritional status in childhood and this may underlie the inverse associations between height and adulthood cardiorespiratory mortality. Much of the association between height and cardiorespiratory mortality was accounted for by lung function, which is also partly determined by exposures acting in child-
The suggestion that stature is inversely related to the risk of disease and mortality dates back to the late 19 th century. ${ }^{1}$ Insurance industry data from the early decades of the 20th century demonstrated that taller people, on average, lived longer than shorter people. ${ }^{2}$ More recently height has been investigated in relation to coronary heart disease (CHD) risk, with case-control and prospective studies identifying inverse associations of height with the extent of atherosclerosis, ${ }^{3} \mathrm{CHD}$ incidence and CHD mortality. ${ }^{4-7} \mathrm{~A}$ few studies have examined other illnesses and have generally, ${ }^{7-10}$ but not always, ${ }^{11}$ found inverse associations of height with stroke. Inverse associations have been found with respiratory disease risk, ${ }^{7}$ and inconsistent results with respect to cancer. ${ }^{7} 10$

Several mechanisms have been advanced to account for the associations that have been found. Firstly, height could serve as an indicator of growth, nutrition and social environment in earlier life. Poor fetal development ${ }^{13}$ and poor growth during childhood ${ }^{14}$ have been associated with increased cardiovascular disease risk in adulthood, as have indicators of unfavourable social circumstances in childhood. ${ }^{15-17}$ Conversely, a high calorie intake in childhood may be related to an increased risk of cancer in later life. ${ }^{18}$ Secondly, height is related to social class in adulthood and thus socially patterned exposures-including health related behaviours, psychosocial influences, environmental factors and the physiological consequences of these-could account for the observed disease associations. Thirdly, the early stages of disease could lead to reductions in height and this process could generate the relation between height and mortality. ${ }^{7}$

The studies of height and mortality that had been published to date have suffered from one or more of a series of limitations: they tend to be restricted to men; they have often used data sources in which information on socioeconomic position, cardiorespiratory disease risk factors and health related behaviours have not 
been available; and they have generally involved small samples, so cause-specific mortality could not be examined. This study overcomes these limitations and presents a detailed analysis of height and mortality among a representative population sample of men and women from the West of Scotland.

\section{Methods}

The Renfrew/Paisley general population study was carried out between 1972 and 1976: the sampling frame was residents of the towns of Renfrew and Paisley aged 45-64 years, and a near $80 \%$ response rate was achieved. Full details of the study methodology have been reported previously. ${ }^{19}$ A questionnaire was completed by each participant and this was checked when the participant attended a screening examination. The questionnaire recorded smoking habit, occupation, respiratory and cardiovascular symptoms. Social class was determined by regular occupation, according to the Registrar General's classification. ${ }^{20}$ In the case of retired people, the last full time occupation was taken. For housewives, husbands' or fathers' occupations were used. Participants were classified as non-manual if they were in social classes I, II or IIIN and manual if in social classes IIIM, IV or V. Blood pressure, height (to the nearest centimetre) and weight were measured and an electrocardiogram was recorded at the screening examination. A non-fasting blood sample was also taken to measure plasma cholesterol concentration. Forced expiratory volume in one second $\left(\mathrm{FEV}_{1}\right)$ was measured and is treated both as a simple continuous variable and as an "FEV score", expressed as a percentage of the expected $\mathrm{FEV}_{1}$ for age and height, calculated from the subset of healthy never smoking participants. $^{21}$

The six lead electrocardiogram (leads I, II, III, AVr, AVl and AVf) was taken with the subject sitting. Criteria for myocardial ischaemia on ECG were based on the Minnesota coding scheme. Any of the following codes were considered evidence of ischaemia, encompassing diagnoses of definite myocardial infarction, myocardial ischaemia and left bundle branch block: 1.1-1.3, 4.1-4.4, 5.1-5.3, 7.1. Angina was considered present if the definite or possible criteria of the Rose Angina Questionnaire were met. ${ }^{22}$ Bronchitis was classified according to responses to the Medical Research Council questionnaire. ${ }^{23}$

The home address at the time of screening was retrospectively postcoded, enabling an area-based deprivation category at the time of the 1981 census to be ascertained. ${ }^{24}$ Deprivation category varies from 1 (least deprived) to 7 (most deprived). Deprivation category and individual social class are related independently to mortality in the study population. ${ }^{25} \mathrm{~A}$ total of 7052 men and 8354 women were included in the study. This differs slightly from numbers given in previous publications $(7058$ men and 8353 women) as 13 miscodings of sex and five people who attended twice were recently discovered.
Height data were missing for three men and 10 women, who were excluded from all analyses. The analyses were therefore performed on 7049 men and 8344 women. For seven participants addresses could not be postcoded and assigned a deprivation category and 423 participants had given insufficient information on occupation to assign a social class. Dummy variables were created for these participants for inclusion in multivariable analyses. Participants were flagged at the National Health Service Central Register in Edinburgh and notification of deaths have been received for a 20 year follow up period. Cause of deaths were coded to ICD9 ${ }^{26}$ We classified the following as smoking related cancers; lip (ICD-9 140); tongue (141); mouth and pharynx (143-9); oesophagus (150); pancreas (157); respiratory tract $(160-163)$ and urinary tract $(188-189) .{ }^{18}$

As height was measured to the nearest centimetre the approximate quintile groups showed some variation in size. Analyses were conducted by height quintile and also according to a 10 centimetre lower height, assuming a linear relation between height and outcome. Age adjusted means for continuous variables were calculated using PROC GLM of the SAS system. Categorical variables were age standardised by the direct method, using the male and female study populations as the standard. Age adjusted mortality rates were calculated using a person years at risk based lifetable approach and age standardisation was by the direct method. Trend tests were obtained through proportional hazards regression using PROC PHREG. Proportional hazards regression analyses of the whole cohort were stratified by sex within the PROC PHREG routine in SAS; except where sex specific analyses have been reported. The exponentiated proportional hazards regression coefficients are referred to as relative rates.

\section{Results}

For men the mean height was $169.6 \mathrm{~cm}$ (standard deviation 6.8; first centile $154 \mathrm{~cm}$ and 99th centile 185). For women the mean height was $157.7 \mathrm{~cm}$ (standard deviation 6.1; first centile $143 \mathrm{~cm}$ and 99th centile 172). The characteristics of the population according to height are presented in table 1 . For both men and women greater height was associated with younger age at screening, therefore data on all other factors were age adjusted. Taller participants were less likely to come from social class IV and V, less likely to live in deprived areas, less likely to report angina or bronchitis on a screening questionnaire, more likely to be ex-smokers, and less likely to have ischaemia detected on an ECG than shorter participants. Taller participants had higher $\mathrm{FEV}_{1}$ than shorter participants and for women, but not men, this was also true for $\mathrm{FEV}_{1}$ score. For men, but not women, taller participants had slightly higher blood pressure and were less likely to be current cigarette smokers than shorter participants. For women, but not men, taller participants had lower plasma cholesterol concentrations and lower body mass index than shorter participants. 
Table 1 Risk factors according to height quintiles (age adjusted means or proportions)

\begin{tabular}{|c|c|c|c|c|c|c|}
\hline \multirow[b]{2}{*}{ Men } & \multicolumn{5}{|c|}{ Height quintile } & \multirow[b]{2}{*}{ Trend ${ }^{\star}$} \\
\hline & $\leqslant 163 \mathrm{~cm}$ & $164-167 \mathrm{~cm}$ & $168-170 \mathrm{~cm}$ & $171-174 \mathrm{~cm}$ & $\geqslant 175 \mathrm{~cm}$ & \\
\hline Number & 1281 & 1359 & 1305 & 1480 & 1624 & \\
\hline Mean age at screening $(y) \dagger$ & 55.2 & 54.7 & 54.2 & 53.8 & 53.1 & $\mathrm{p}=0.0001$ \\
\hline Mean diastolic BP (mm Hg) & 85.8 & 85.5 & 86.4 & 85.5 & 86.9 & $\mathrm{p}=0.019$ \\
\hline Mean cholesterol ( $\mathrm{mmol} / \mathrm{l})$ & 5.87 & 5.85 & 5.87 & 5.85 & 5.87 & $\mathrm{p}=0.60$ \\
\hline Mean body mass index $\left(\mathrm{kg} / \mathrm{m}^{2}\right)$ & 25.9 & 25.9 & 26.0 & 25.8 & 25.8 & $\mathrm{p}=0.29$ \\
\hline Mean $\mathrm{FEV}_{1}(\mathrm{l})$ & 2.18 & 2.37 & 2.49 & 2.63 & 2.82 & $\mathrm{p}=0.0001$ \\
\hline Mean adjusted $\mathrm{FEV}_{1}(\%)$ & 88.3 & 88.2 & 88.2 & 89.4 & 88.9 & $\mathrm{p}=0.10$ \\
\hline$\%$ never smoked & 17.5 & 17.1 & 16.5 & 16.4 & 16.4 & $\mathrm{p}=0.35$ \\
\hline$\%$ current cigarette smokers & 61.4 & 58.2 & 54.2 & 55.9 & 54.5 & $\mathrm{p}=0.0003$ \\
\hline$\%$ ex smokers & 19.5 & 22.2 & 27.0 & 25.7 & 27.6 & $\mathrm{p}=0.0001$ \\
\hline$\%$ deprivation category $5-7$ & 68.2 & 62.6 & 59.6 & 53.1 & 49.7 & $\mathrm{p}=0.0001$ \\
\hline$\%$ social class IV and V & 37.7 & 31.2 & 28.6 & 25.6 & 22.4 & $\mathrm{p}=0.0001$ \\
\hline$\%$ angina (definite and possible) & 21.6 & 18.9 & 17.5 & 15.2 & 15.3 & $\mathrm{p}=0.0001$ \\
\hline$\%$ bronchitis & 7.6 & 6.4 & 6.4 & 4.4 & 4.5 & $\mathrm{p}=0.0001$ \\
\hline \multirow[t]{2}{*}{$\% \mathrm{ECG}$ ischaemia } & 12.4 & 10.5 & 10.1 & 9.3 & 10.2 & $\mathrm{p}=0.036$ \\
\hline & \multicolumn{2}{|c|}{ Height quintile } & & & & \\
\hline Women & $\leqslant 152 \mathrm{~cm}$ & $153-155 \mathrm{~cm}$ & $156-158 \mathrm{~cm}$ & $159-162 \mathrm{~cm}$ & $\geqslant 163 \mathrm{~cm}$ & Trend $^{\star}$ \\
\hline Number & 1638 & 1378 & 1606 & 2003 & 1719 & \\
\hline Mean age at screening $(y) \dagger$ & 55.9 & 54.9 & 54.5 & 53.9 & 53.0 & $\mathrm{p}=0.0001$ \\
\hline Mean diastolic BP (mm Hg) & 85.4 & 85.6 & 84.8 & 84.9 & 85.2 & $\mathrm{p}=0.53$ \\
\hline Mean cholesterol $(\mathrm{mmol} / \mathrm{l})$ & 6.49 & 6.45 & 6.42 & 6.42 & 6.35 & $\mathrm{p}=0.001$ \\
\hline Mean body mass index $\left(\mathrm{kg} / \mathrm{m}^{2}\right)$ & 26.5 & 26.2 & 25.8 & 25.8 & 25.0 & $\mathrm{p}=0.0001$ \\
\hline Mean $\mathrm{FEV}_{1}(\mathrm{l})$ & 1.55 & 1.66 & 1.78 & 1.84 & 2.00 & $\mathrm{p}=0.0001$ \\
\hline Mean adjusted $\mathrm{FEV}_{1}(\%)$ & 90.3 & 90.9 & 93.6 & 92.8 & 94.4 & $\mathrm{p}=0.0001$ \\
\hline$\%$ never smoked & 45.8 & 46.6 & 46.2 & 44.9 & 45.3 & $\mathrm{p}=0.11$ \\
\hline$\%$ current cigarette smokers & 48.5 & 47.7 & 45.6 & 47.2 & 45.0 & $\mathrm{p}=0.29$ \\
\hline$\%$ ex smokers & 5.5 & 5.7 & 8.2 & 7.8 & 9.6 & $\mathrm{p}=0.0001$ \\
\hline$\%$ deprivation category $5-7$ & 66.9 & 60.6 & 58.5 & 56.7 & 50.9 & $\mathrm{p}=0.0001$ \\
\hline$\%$ social class IV and V & 48.3 & 42.3 & 39.8 & 35.0 & 29.2 & $\mathrm{p}=0.0001$ \\
\hline$\%$ angina (definite and possible) & 20.9 & 17.0 & 17.2 & 15.9 & 13.9 & $\mathrm{p}=0.0001$ \\
\hline$\%$ bronchitis & 6.5 & 3.8 & 4.2 & 3.1 & 3.2 & $\mathrm{p}=0.0001$ \\
\hline$\%$ ECG ischaemia & 10.8 & 11.5 & 9.6 & 9.7 & 8.6 & $\mathrm{p}=0.021$ \\
\hline
\end{tabular}

*Using height as a continuous variable. $†$ Not age adjusted.

Table 2 shows the mortality rates and relative rates associated with $10 \mathrm{~cm}$ lower height. All cause, coronary heart disease, stroke and respiratory disease mortality are inversely related to height. For both sexes respiratory disease is the cause of death most strongly associated with height. For men stroke is more strongly associated with height than coronary heart disease, while there is little difference for women. Adjustment for socioeconomic, behavioural and physiological risk factors had little influence on the association between height and mortality. In these adjustments the $\mathrm{FEV}_{1}$ score was used as the measure of lung function. Raw $\mathrm{FEV}_{1}$ is strongly correlated with height $(r=0.38$ for men and $r=0.37$ for women), and several studies have suggested that lung function accounts for the association of height with cardiovascular mortality and morbidity. ${ }^{4}$ Including raw $\mathrm{FEV}_{1}$ rather than $\mathrm{FEV}_{1}$ score among the factors adjusted for resulted in considerable attenuation of the associations between height and cardiorespiratory mortality, with relative rates for $10 \mathrm{~cm}$ lower height in men being $1.02(95 \%$ CI $0.93,1.11)$ for coronary heart disease; $1.19(0.99,1.42)$ for stroke and $0.91(0.75,1.09)$ for respiratory disease mortality in the fully adjusted models. For women the equivalent relative rates were $1.08(0.95,1.22)$ for coronary heart disease; $1.10(0.92,1.31)$ for stroke and $1.28(0.99$, 1.65) for respiratory disease mortality. We also examined the associations between raw $\mathrm{FEV}_{1}$ and cardiorespiratory mortality (table 3 ). The strong associations found were little influenced by adjustment for height.

Smoking related cancer mortality is not associated with height (table 2). Mortality from smoking unrelated cancers tended to be positively associated with height, although there was considerable heterogeneity within this category. Table 4 shows that stomach cancer is inversely associated with height. Mortality from haematopoietic cancers, colorectal cancer and prostate cancer tended to be directly related to height, while breast cancer was unrelated to height. The association between height and haematopoietic cancer was largely limited to lymphoma (ICD 200-203), with an age adjusted combined relative rate of $0.44(0.29,0.65)$ for $10 \mathrm{~cm}$ lower height; for leukaemia (ICD 204-208) the equivalent relative rate was $0.89(0.46,1.72)$. There were no significant interactions between height and sex in any of these analyses.

For all cause and cardiorespiratory disease mortality, associations were analysed separately for the first 10 years and second 10 years of follow up. The only finding consistent between sexes was that the association between height and respiratory disease mortality was considerably stronger over the initial 10 year follow up period than the later period. For men the relative rate for $10 \mathrm{~cm}$ lower height over the first 10 years of follow up was $1.75(1.32,2.33)$; over the second 10 years this was $1.28(1.03,1.61)$. For women the equivalent relative rates were $2.20(1.51,3.20)$ and $1.58(1.21,2.07)$.

\section{Discussion}

Height in this large general population study is inversely associated with all cause mortality among men and women over a 20 year follow up period. The strength and direction of the association between height and mortality varies 
Table 2 Age adjusted 20 year mortality (per 10000 person years) in the Renfrew/Paisley Study by height quintile

\begin{tabular}{|c|c|c|c|c|c|c|c|}
\hline \multirow[b]{2}{*}{$\operatorname{Men}(n=7049)$} & \multicolumn{5}{|c|}{ Height quintile } & \multirow[b]{2}{*}{$R R^{\star}(95 \% C I)$} & \multirow[b]{2}{*}{$R R+(95 \% C I)$} \\
\hline & $\leqslant 163 \mathrm{~cm}$ & $164-167 \mathrm{~cm}$ & $168-170 \mathrm{~cm}$ & $171-174 \mathrm{~cm}$ & $\geqslant 175 \mathrm{~cm}$ & & \\
\hline \multicolumn{8}{|l|}{ All cause } \\
\hline Number of deaths & 685 & 704 & 600 & 661 & 697 & & \\
\hline Mortality rate & 257.5 & 255.5 & 234.7 & 232.5 & 233.1 & $1.13(1.07,1.19)$ & $1.10 \ddagger(1.04,1.16)$ \\
\hline \multicolumn{8}{|l|}{ CHD } \\
\hline Number of deaths & 278 & 248 & 238 & 251 & 266 & & \\
\hline Mortality rate & 132.6 & 115.1 & 111.6 & 105.3 & 107.5 & $1.14(1.05,1.24)$ & $1.12 \ddagger(1.03,1.22)$ \\
\hline \multicolumn{8}{|l|}{ Stroke } \\
\hline Number of deaths & 74 & 64 & 57 & 59 & 48 & & \\
\hline Mortality rate & 43.3 & 38.5 & 33.0 & 32.9 & 25.6 & $1.32(1.11,1.57)$ & $1.30 \ddagger(1.10,1.55)$ \\
\hline \multicolumn{8}{|l|}{ Respiratory disease } \\
\hline Number of deaths & 69 & 72 & 51 & 40 & 48 & & \\
\hline Mortality rate & 36.9 & 42.0 & 30.9 & 22.6 & 23.6 & $1.45(1.21,1.72)$ & $1.35 \rrbracket(1.12,1.61)$ \\
\hline \multicolumn{8}{|l|}{ Smoking related cancer } \\
\hline Number of deaths & 115 & 129 & 109 & 131 & 148 & & \\
\hline Mortality rate & 61.5 & 63.0 & 55.0 & 59.6 & 64.1 & $1.03(0.91,1.15)$ & $0.96 \rrbracket(0.86,1.09)$ \\
\hline \multicolumn{8}{|c|}{ Smoking unrelated cancer } \\
\hline \multirow{3}{*}{ Mortality rate } & 60 & 81 & 64 & 70 & 90 & & \\
\hline & 35.2 & 43.7 & 35.2 & 35.9 & 40.5 & $0.92(0.79,1.07)$ & $0.88 \uparrow(0.75,1.03)$ \\
\hline & \multicolumn{2}{|c|}{ Height quintile } & & & & & \\
\hline Women $(n=8344)$ & $\leqslant 152 \mathrm{~cm}$ & $153-155 \mathrm{~cm}$ & $156-158 \mathrm{~cm}$ & $159-162 \mathrm{~cm}$ & $\geqslant 163 \mathrm{~cm}$ & $R R^{\star}(95 \% C I)$ & $R R+(95 \% C I)$ \\
\hline \multicolumn{8}{|l|}{ All cause } \\
\hline Number of deaths & 632 & 473 & 515 & 598 & 420 & & \\
\hline Mortality rate & 177.6 & 168.0 & 160.7 & 156.9 & 137.4 & $1.19(1.11,1.26)$ & $1.16 \neq(1.08,1.23)$ \\
\hline \multicolumn{8}{|l|}{ CHD } \\
\hline Number of deaths & 208 & 149 & 130 & 179 & 105 & & \\
\hline Mortality rate & 69.0 & 61.2 & 48.3 & 54.8 & 40.3 & $1.29(1.15,1.45)$ & $1.22 \ddagger(1.08,1.37)$ \\
\hline \multicolumn{8}{|l|}{ Stroke } \\
\hline Number of deaths & 101 & 78 & 75 & 75 & 57 & & \\
\hline Mortality rate & 35.2 & 34.9 & 30.5 & 27.7 & 25.9 & $1.23(1.04,1.45)$ & $1.20 \ddagger(1.02,1.43)$ \\
\hline \multicolumn{8}{|l|}{ Respiratory disease } \\
\hline Number of deaths & 54 & 43 & 36 & 32 & 23 & & \\
\hline Mortality rate & 19.1 & 19.6 & 15.2 & 10.5 & 9.6 & $1.75(1.40,2.18)$ & $1.77 \rrbracket(1.38,2.27)$ \\
\hline \multicolumn{8}{|l|}{ Smoking related cancer } \\
\hline Number of deaths & 62 & 35 & 55 & 80 & 62 & & \\
\hline Mortality rate & 22.8 & 15.0 & 20.7 & 24.2 & 22.6 & $0.98(0.81,1.18)$ & $1.01 \rrbracket(0.83,1.23)$ \\
\hline \multicolumn{8}{|c|}{ Smoking unrelated cancer } \\
\hline Number of deaths & 94 & 94 & 123 & 136 & 107 & & \\
\hline Mortality rate & 32.5 & 40.3 & 44.5 & 39.4 & 35.3 & $0.93(0.81,1.07)$ & 0.89 ( $(0.77,1.02)$ \\
\hline
\end{tabular}

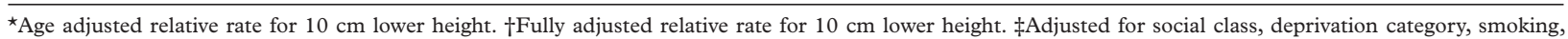
diastolic blood pressure, cholesterol, body mass index, and FEV score. \$Adjusted for social class, deprivation category, smoking, body mass index and FEV score. -Adjusted for social class, deprivation category, body mass index and FEV score.

Table 3 Age adjusted relative rates (95\% CI) for a one standard deviation lower FEV, with and without additional height adjustment

\begin{tabular}{llll}
\hline & CHD & Stroke & Respiratory disease \\
\hline $\begin{array}{llll}\text { Men } \\
\text { age }\end{array}$ & $1.28(1.21,1.36)$ & $1.38(1.22,1.55)$ & $3.55(3.14,4.01)$ \\
$\begin{array}{l}\text { age/height } \dagger \\
\begin{array}{l}\text { agen } \\
\text { age/height }\end{array}\end{array}$ & $1.27(1.20,1.36)$ & $1.33(1.17,1.51)$ & $3.60(3.18,4.07)$ \\
& $1.42(1.31,1.53)$ & $1.34(1.20,1.49)$ & $2.77(2.39,3.20)$ \\
\hline
\end{tabular}

^Adjusted for age. †Adjusted for age and height.

between broad cause of death groups, however. Among both men and women respiratory disease mortality is most strongly associated with height, with inverse associations also being seen for cardiovascular disease mortality. Among men the association is stronger with respect to stroke than coronary heart disease, although among women there is little difference between these associations. Stomach cancer mortality is inversely associated with height, while smoking related cancer mortality is not associated with height. Mortality from smoking unrelated cancers, with the exception of stomach cancer, tends to be positively associated with height: taller people experience higher mortality rates.

GENERAL EXPLANATIONS OF HEIGHT-MORTALITY ASSOCIATIONS

Two possible general explanations of inverse associations between height and mortality need to be considered. Firstly, height is associated with socioeconomic position: people in better socioeconomic circumstances are, on average, taller. This is shown in our own data with respect to occupational social class and areabased deprivation measures. Confounding by socioeconomic position would, then, be expected to produce inverse associations between height and mortality. If this explanation were the case then these associations should be seen for all causes of death that show strong

Table 4 Relative rates (95\% CI) for $10 \mathrm{~cm}$ lower height for cancers unrelated to smoking

\begin{tabular}{llllll}
\hline & Number & Male $R R^{\star}$ & Female $R R^{\star}$ & Combined RR* & Combined RRt \\
\hline All smoking unrelated cancers & 919 & $0.92(0.79,1.07)$ & $0.93(0.81,1.07)$ & $0.92(0.83,1.02)$ & $0.89(0.80,0.99)$ \\
Stomach (ICD 151) & 103 & $1.43(0.95,2.14)$ & $1.54(0.98,2.41)$ & $1.47(1.09,1.99)$ & $1.33(0.97,1.80)$ \\
Colorectal (ICD 153-4) & 201 & $0.71(0.53,0.96)$ & $0.80(0.58,1.10)$ & $0.75(0.60,0.94)$ & $0.70(0.56,0.88)$ \\
Breast (ICD 174) & 147 & - & $1.13(0.86,1.48)$ & - & - \\
Prostate (ICD 185) & 59 & $0.77(0.53,1.14)$ & - & - & - \\
Haematopoietic (ICD 200-8) & 79 & $0.63(0.39,1.03)$ & $0.45(0.28,0.73)$ & $0.53(0.38,0.75)$ & $0.52(0.36,0.73)$ \\
Other (remainder) & 330 & $1.14(0.87,1.49)$ & $0.90(0.72,1.13)$ & $0.99(0.83,1.18)$ & $0.98(0.82,1.17)$ \\
\hline
\end{tabular}

*Adjusted for age. †Adjusted for age, social class and deprivation category. 
socioeconomic gradients. Smoking related cancers demonstrate some of the strongest associations with adverse socioeconomic circumstances, ${ }^{27}$ however they are not related to height. This argues against socioeconomic confounding as being key to the heightmortality associations, as does the robustness of the associations to adjustment for social class and area-based deprivation scores in the present data.

Secondly, early stages of disease could lead to a loss of height. ${ }^{7}$ This could either be real, because of disc space compression, or apparent, because of inability to stretch during height measurement. In either case the lower measured height, on average, of the sick would produce inverse height-mortality associations. ? This has been explored in a previous study by analysing mortality during earlier and later periods of mortality follow up. Such reverse causation should produce stronger inverse associations in the earlier period of follow up, because as people with pre-existing disease die and are removed from the cohort they contribute less and less to the height-mortality associations. In an earlier study such attenuation over time was seen for both respiratory disease and coronary heart disease mortality. ${ }^{7}$ In the present data such attenuation was only convincingly demonstrated for respiratory disease mortality. This suggests that such reverse causality is mainly an issue with respect to respiratory disease, a finding that is biologically plausible.

HEIGHT AND CAUSE SPECIFIC MORTALITY

There are several factors, indexed by short stature, which could be responsible for the associations between height and mortality. Adult height is influenced by fetal development (indexed by birth weight), and growth during pregnancy and adolescence. ${ }^{28}$ Factors that result in reduced birth weights - such as poor maternal nutrition and smoking-may, therefore, influence adult height. Genetic factors are also clearly of importance, although these could not be investigated in this study. Nutrition in infancy and adolescence are reflected in final adult height. Adverse social circumstances during childhood are also related to shorter stature in adulthood. ${ }^{28}$ It is notable that in this study height is inversely associated with risk of stomach cancer, stroke, CHD and respiratory disease mortality. In a separate Scottish cohort we have demonstrated that adverse social circumstances in childhood-indexed by paternal occupational social class - are associated with high rates of mortality from these causes. ${ }^{17}$

Early life determinants of stomach cancer mortality are implicated by ecological correlations between present day stomach cancer rates and indicators of adverse social circumstances, at the time when the cohorts who are currently developing stomach cancer were children. ${ }^{29}$ Helicobacter pylori infection is generally acquired in childhood and this has been shown to be related to overcrowded housing and poor sanitary environments. ${ }^{30}$ Helicobacter pylori infection persisting from childhood is an impor-
KEY POINTS

- Greater height is associated with reduced risk of coronary heart disease, stroke and respiratory death.

- Lung function is an important mediator of the association between height and cardiorespiratory mortality.

- Greater height is associated with increased risk of several cancers unrelated to smoking.

- The association between height and cancer may reflect the influence of calorie intake during childhood.

tant cause of stomach cancer ${ }^{31}$ and is also associated with poorer growth and shorter attained height. $^{32}{ }^{33}$ Thus the inverse association between height and stomach cancer mortality, also seen in a previous study, ${ }^{34}$ could reflect chronic Helicobacter pylori infection.

The higher stroke, CHD and respiratory disease mortality of people who experienced worse social circumstances in childhood is seen after socioeconomic position and cardiorespiratory risk factors in adulthood are taken into account. ${ }^{17}$ Similarly, in the present data adjusting for indicators of adulthood socioeconomic position, blood pressure, smoking, body mass index, cholesterol and $\mathrm{FEV}_{1}$ score had little effect on the inverse association between height and cardiovascular mortality; a more substantial attenuation of the association between height and respiratory disease mortality was seen, although a substantial residual effect remained. Adjustment for raw $\mathrm{FEV}_{1}$ greatly attenuated the associations between height and cardiorespiratory mortality, however. There has been considerable debate in the literature as to the appropriateness of adjusting for raw lung function measures when assessing the association between height and mortality. ${ }^{45-39}$ Height is strongly correlated with raw $\mathrm{FEV}_{1}$, in part simply because taller people have larger lungs. Thus adjusting for raw $\mathrm{FEV}_{1}$ is adjusting for a proxy for height itself. In the present data, as in an earlier study, ${ }^{35}$ it is noticeable that adjusting height-mortality associations for raw $\mathrm{FEV}_{1}$ greatly attenuates the relative rates, while adjusting raw $\mathrm{FEV}_{1}$-mortality associations for height has virtually no effect. If the problem was simply one of collinearity it should influence both sets of adjustments. $\mathrm{FEV}_{1}$ score is an index of lung health, while raw $\mathrm{FEV}_{1}$ is an index of both lung health and lung capacity. In this simplified scheme, lung health includes a component attributable to airways geometry that is not proportional to height. ${ }^{40}$ Raw FEV is thus influenced both by body dimensions and by exposures acting across the lifecourse that influence lung function in adulthood. These factors include fetal development, childhood chest illnesses, smoking and occupational exposures in adulthood. ${ }^{41}$ Adjustment for raw $\mathrm{FEV}_{1}$ may, therefore, be equivalent to adjusting for a sensitive index of accumulating exposures acting across the lifecourse. ${ }^{42}$

The associations between adult height and cancer have been inconsistent across cancer 
sites, for cancer incidence or cancer mortality and between studies, ${ }^{71} 124344$ although generally it is cancers unrelated to smoking that are found to be positively associated with height. ${ }^{1245}$ The positive associations we found between height and prostate cancer, colorectal cancer and lymphoma have been seen in most, but not all, previous studies. ${ }^{71} 4344$ In most previous studies height has been positively associated with breast cancer risk, ${ }^{46}$ although we did not find this. The interpretation of positive height-cancer associations has focused on caloric intake in early life as a determinant of both height and later cancer risk, ${ }^{12}{ }^{45}$ a suggestion that is strengthened by the recent demonstration of a direct association between energy intake in childhood and later risk of nonsmoking related cancers. ${ }^{18}$ Animal experiments have repeatedly demonstrated that caloric restriction from early age reduces the risk of cancer in later life. ${ }^{47}$ Recent reports of positive associations between insulin-like growth factor-I levels and prostate, colon and breast cancer provide a possible mechanism for the above associations. ${ }^{48-50}$ Calorie restricted diets that decrease cancer risk in animals also decrease IGF-I levels. ${ }^{51}$ Height may serve as an indicator of IGF-I levels during growth and developmental phases, ${ }^{52}$ which has been proposed as the period during which IGF-I levels act to increase cancer risk in later life. ${ }^{50}$

Height may reflect other early life exposures, such as the absence or delay of childhood infections. Large sibships, which are associated with shorter height, have been associated with a reduced risk of Hodgkin's disease. ${ }^{53}$ In another study in the West of Scotland ${ }^{17}$ we have found an inverse association between number of siblings and risk of mortality from lymphoma (Davey Smith and Hart, unpublished observations).

Long term secular trends in height have been associated with changing mortality rates in Britain and elsewhere. ${ }^{54}$ In Britain for people born during the second quarter of the 19th century height decreased with year of birth, then increased for people born after the mid-century. ${ }^{54}$ This pattern is strikingly similar to mortality trends. All cause mortality showed no improvement (and in some places even increased) over the second quarter of the century, and then from around 1850 mortality reductions were seen in a cohort specific manner, first for children, then for young adults and then for older adults. ${ }^{556}$ Both the height and mortality data suggest that childhood circumstances started to improve around the middle of the 19th century and that people who were young children during this period took with them, as their cohort aged, a reduced mortality risk. Our data on the cause specific associations of mortality and height suggest that a similar co-dependency of height and mortality may be occurring presently. Height in Britain has continued to increase throughout the second half of the 20th century. ${ }^{57}$ The causes of death that are inversely associated with height are those that tend to be decreasing, such as stroke, stomach cancer and respiratory disease mortality. The causes of death that show a positive association with height are those showing less favourable trends, such as prostate cancer, lymphoma and colorectal cancer. The factors that underlie the secular trend of increasing height in the population may also be influencing cause specific mortality rates. Plausible underlying factors include increasing net energy balance (that is, energy intake minus that expended in physical activity, in keeping warm, etc) intake in childhood, and decreases and delays in infection in childhood..$^{58}$

The authors thank Anne Rennie and Liz Humphries for processing the manuscript and to Pauline Mackinnon for mainprocessing the manuscript and
tenance of the cohort database.

Funding: these analyses were funded by the Stroke Association and Chest, Heart and Stroke Scotland.

Conflicts of interest: none.

1 British Association for the Advancement of Science. Final report of the Anthropometric Committee. London: British Association, 1883

2 Dublin LI, Lotka AJ, Spiegelman M. Length of life: a study of the life table. New York: The Ronald Press Company, 1949.

3 Nwasokwa ON, Weiss M, Gladstone C, et al. Higher prevalence and greater severity of coronary disease in short versus tall men referred for coronary arteriography. Am Heart f 1997; 133:147-52

4 Walker M, Shaper AG, Phillips AN, et al. Short stature, lung function and risk of a heart attack. Int f Epidemiol 1989;18: 602-6.

5 Palmer JR, Rosenberg L, Shapiro S. Stature and the risk of myocardial infarction in women. Am f Epidemiol 1990;132: 27-32.

6 Yarnell JGW, Limb ES, Layzell JM, et al. Height: a risk marker for ischaemic heart disease. Eur Heart $\mathcal{F}$ 1992;13: marker for

7 Leon D, Davey Smith G, Shipley M, et al. Adult height and mortality in London: early life, socioeconomic confoundng or shrinkage? F Epidemiol Community Health 1995;49:5-

8 Njolstad I, Arnesen E, Lund-Larsen PG. Body height, cardiovascular risk factors, and risk of stroke in middleaged men and women. A 14-year follow-up of the Finnmark Study. Circulation 1996;94:2877-82.

9 Walker SP, Rimm EB, Ascherio A, et al. Body size and fat distribution as predictors of stroke among US men. $A m \mathcal{F}$ Epidemiol 1996;144:1143-50.

10 Tverdal A. A mortality follow-up of persons invited to a cardiovascular disease study in five areas in Norway. Oslo: National Health Screening Service, 1989.

11 Wannamethee SG, Shaper AG, Whincup PH, et al. Adult height, stroke and coronary heart disease. Am f Epidemiol; 148:1069-76.

12 Davey Smith G, Shipley M, Leon D. Height and cancer mortality among men: prospective observational study. BMF 1998;317:1351-2.

13 Barker DJP. Mothers, babies, and disease in later life. London: BMJ Publishing Group, 1994.

14 Gunnell DJ, Davey Smith G, Frankel SJ, et al. Childhood leg length and adult mortality: follow up of the Carnegie (Boyd Orr) survey of diet and health in pre-war Britain. $\mathcal{F}$ Epidemiol Community Health 1998;52:142-52.

15 Davey Smith G, Hart C, Blane D, et al. Lifetime socioeconomic position and mortality: prospective observational study. BMF 1997;314:547-52.

16 Wannamethee SG, Whincup PH, Shaper G, et al. Influence of fathers'social class on cardiovascular disease in middleaged men. Lancet 1996;348:1259-63.

17 Davey Smith G, Hart C, Blane D, et al. Adverse socioeconomic conditions in childhood and cause-specific adult mortality: prospective observational study. BMF 1998;316:1631-5.

18 Frankel S, Gunnell DJ, Peters TJ, et al. Childhood energy intake and adult cancer - The Boyd Orr cohort study. BMF 1998;316:499-504.

19 Hawthorne VM, Watt GCM, Hart CL, et al. Cardiorespiratory disease in men and women in urban Scotland: baseline characteristics of the Renfrew/Paisley (Midspan) population study. Scott Med F 1995;40:102-7.

20 Anonymous. General Register office classification of occupations. London: HMSO, 1966.

21 Hole DJ, Watt GCM, Davey Smith G, et al. Impaired lung function and mortality risk in men and women: findings from the Renfrew and Paisley prospective population study. BMF 1996;313:711-15.

22 Rose GA, Blackburn H, Gillum RF, et al. Cardiovascular survey methods. Geneva: WHO, 1982.

23 Medical Research Council. Definition and classification of chronic bronchitis for epidemiological purposes. Lancet 1965; i:775-9.

24 Carstairs V, Morris R. Deprivation and health in Scotland. Aberdeen: Aberdeen University Press, 1991.

25 Davey Smith G, Hart C, Watt G, et al. Individual social class, area-based deprivation, cardiovascular disease riskfactors and mortality: the Renfrew and Paisley study. F Epidemiol Community Health 1998;52:399-405. 
26 World Health Organisation. Manual of the international, statistical classification of diseases, injuries, and causes of death tistical classification of diseases, injur

27 Davey Smith G, Leon D, Shipley MJ. Socioeconomic differentials in cancer among men. Int $\mathcal{F}$ Epidemiol 1991;20:33945.

28 Eveleth PB, Tanner JM. World-wide variation in human growth. 2nd ed. Cambridge: Cambridge University Press, 1990.

29 Barker DJP, Coggon D, Osmond C, et al. Poor housing in childhood and high rates of stomach cancer in England and Wales. Br 7 Cancer 1990;61:575-8.

30 Malaty HM, Graham DY. Importance of childhood socioeconomic status on the current prevalence of Helicobacter pylori infection. Gut 1994;35:742-5.

31 Forman D, Newell DG, Fullerton F, et al. Association between infection with Helicobacter pylori and risk of gastric cancer: evidence from a prospective investigation. BMF 1991;302:1302-5

32 Patel P, Mendall M, Khulusi S, et al. Helicobacter pylori infection in childhood: risk factors and effect on growth. infection in childhood: risk

33 Mendall M, Molineaux N, Levy J, et al. Association of $\mathrm{H}$ pylori with diminished adult height. Gut 1994;35:S4

34 Hansson L-E, Baron J, Nyrén O, et al. Early-life risk indicators of gastric cancer. A population- based case-control study in Sweden. Int $\mathcal{F}$ Cancer 1994;57:32-7.

35 Strachan DP. Ventilatory function, height, and mortality among lifelong non-smokers. F Epidemiol Community Health 1992;46:66-70.

36 Cook NR, Hebert PR, Satterfield S, et al. Height,lung function, and mortality from cardiovascular disease among the elderly. Am 7 Epidemiol 1994;139:1066-76.

37 Rich-Edwards JW, Manson JE, Stampfer MJ, et al. Height and the risk of cardiovascular disease in women. Am f Epidemiol 1995;142:909-17.

38 Walker M, Phillips A, Shaper AG, et al. Re: Height and the risk of cardiovascular disease in women. [Letter]. $A m$, Epidemiol 1996;144:708.

39 Rich-Edwards JW, Manson JE, Hennekens CH. Re: Height and the risk of cardiovascular disease in women. Three and the risk of cardiovascular disease in women. Thre
authors reply. [Letter]. Am 7 Epidemiol 1996;144:708-9.

40 Martin TR, Feldman HA, Fredberg JJ, et al. Relationship Martin TR, Feldman HA, Fredberg JJ, et al. Relationship
between maximal expiratory flows and lung volumes in between maximal expiratory flows and lung vol
growing humans. F Appl Physiol 1988;65:822-8.

41 Strachan DP. Respiratory and allergic diseases. In: Kuh D, Ben-Shlomo Y, eds. A life course approach to chronic disease epidemiology. Oxford: OUP, 1997:101-20.

42 Mann SL, Wadsworth MEJ, Colley JRT. Accumulation of factors influencing respiratory illness in members of a national birth cohort and their offspring. F Epidemiol Community Health 1992;46:286-92.
43 La Vecchia C, Negri E, Parazzini F, et al. Height and cancer risk in a network of case-control studies from Northern risk in a network of case-control
Italy. Int $\mathcal{f}$ Cancer 1990;45:275-9.

44 Hebert PR, Ajani U, Cook NR, et al. Adult height and incidence of cancer in male physicians (United States). Cancer Causes Control 1997;8:591-7.

45 Gunnell DJ, Davey Smith G, Holly JMP, et al. Leg length and cancer risk: indirect evidence of an aetiological role for growth factors in the Boyd Orr Cohort. BMF 1998;317: 1350-1.

46 Vatten LJ. Body size and breast cancer risk. The Breast 1996; 5:5-9.

47 Shimokawa I, Higami Y Effect of dietary restriction on pathological processes. In: Yu BP, ed. Modulation of aging
processes by dietary restriction. London: CRC Press, processes by $1994: 247-66$.

48 Chan JM, Stampfer MJ, Giovannucci E, et al. Plasma insulin-like growth factor-I and prostate cancer risk: a prospective study. Science 1998;279:563-6.

49 Cats A, Dullaart RPF, Kleibeuker JH, et al. Increased epithelial cell proliferation in the colon of patients with acromegaly. Cancer Res 1996;56:523-6.

50 Hankinson SE, Willett WC, Colditz GA, et al. Circulating concentrations of insulin-like growth factor-I and risk of breast cancer. Lancet 1998;351:1393-6.

51 Ruggeri B, Klurfeld D, Kritchevsky D, et al. Calorie restriction and 7,12-dimethylben(a)anthracene-induced mammary tumor growth in rats: alterations in circulating mary tumor growth in rats: alterations in circulating
insulin, insulin-like growth factors I and II, and epidermal growth factor. Cancer Res 1998;49:4135-41.

52 Juul A, Bang P, Hertel NT, et al. Serum insulin-like growth factor I in 1030 healthy children, adolescents, and adults: elation to age, sex, stage of puberty, testicular size, and body mass index. F Clin Endocrinol Metab 1994;78:744-52.

53 Bonelli L, Vitale V, Bistolfi F, et al. Hodgkin's disease in adults: association with social factors and age at tonsillectomy. A case-control study. Int 7 Cancer 1990;45:423-7.

54 Floud R, Wachter K, Gregory A. Height, health and history. Nutritional status in the United Kingdom, 1750-1980. Cambridge: Cambridge University Press, 1990.

55 Kermack WO, McKendrick AG, McKinlay PL. Death rates in Great Britain and Sweden: Some general regularities and their significance. Lancet 1934;226:698-703.

56 Kuh D, Davey Smith G. When is mortality risk determined? Historical insights into a current debate. Social History of Medicine 1993;6:101-23.

57 Kuh DL, Power C, Rodgers B. Secular trends in social class and sex differences in adult height. Int $\mathcal{F}$ Epidemiol 1991;20: 1001-9.

58 Charlton J, Murphy M. The health of adult Britain 1841-1994. London: The Stationery Office, 1997. 